\title{
Analisis Makna Bahasa dan Seni Rupa dalam Gambar Ilustrasi Cerita
}

\author{
Susiloningtyas \\ Universitas Indraprasta PGRI \\ Jl. Nangka No. 58 C/TB. Simatupang, Tanjung Barat, Jakarta Selatan 12530 \\ sn.tyas9@gmail.com
}

\begin{abstract}
The purpose of this research is to find out the meaning of language in the story illustration images and the meaning of fine art in the picture illustration of the story. The results of the study concluded there is a language meaning in the illustration of the story. This is evidenced by the presence of symbolic / meaningful elements in the illustrations in the form of neutral elements $33.3 \%$ Protagonist 50\% Antagonist 16.7\%. The symbolic / meaning element that describes a character with character Protagonist dominates in the illustration, and also found an educational aspect in the form of character education values in the narrative of the story. The aspect of character education values related to rewarding achievement dominates in the narrative. There is a meaning of fine art in the story illustration image. This is evidenced by the existence of elements of the meaning of art in the form of objects of illustration images which include human visual elements $23.7 \%$ animal visual elements $18.42 \%$ plant form elements $10.52 \%$ visual elements $36.84 \%$ Elements of shadows and shadows $0 \%$ elements of the form of points, lines, colors, textures, dark light, space, fields, and volume / stock / shape 10.52\%. The elements of natural objects dominate the elements of the meaning of fine art in the form of illustrated image objects.
\end{abstract}

Keywords: language, fine art, art elements, meaning of images, character education.

\begin{abstract}
Abstrak
Tujuan dari penelitian ini adalah untuk mengetahui makna bahasa dalam gambar ilustrasi cerita dan makna seni rupa dalam gambar ilustrasi cerita. Metode yang digunakan dalam penelitian ini adalah deskriptif kualitatif dengan menggunakan metode penelitian konten analisis dalam menjaring dan memaparkan data yang telah didapat, data deskriptif berupa kata-kata tertulis dari narasi cerita dan bahasa visual dalam gambar ilustrasi cerita. Hasil penelitian disimpulkan bahwa terdapat makna bahasa dalam gambar ilustrasi cerita. Hal ini dibuktikan dengan terdapat unsur simbolik/makna dalam gambar ilustrasi berupa unsur netral 33,3\% Protagonis 50\% Antagonis $16,7 \%$. Unsur simbolik/makna yang menggambarkan tokoh berkarakter Protagonis mendominasi dalam gambar ilustrasi, dan ditemukan pula aspek edukatif berupa nilai-nilai pendidikan karakter di dalam narasi cerita. Aspek nilai pendidikan karakter yang berhubungan dengan menghargai prestasi mendominasi di dalam narasi cerita. Terdapat makna seni rupa dalam gambar ilustrasi cerita. Hal ini dibuktikan dengan terdapat unsur makna seni rupa berupa objek gambar ilustrasi yang meliputi unsur rupa manusia $23,7 \%$ unsur rupa hewan 18,42\% unsur rupa tumbuhan 10,52\% unsur rupa Alam benda 36,84\% Unsur rupa bayang-bayang dan bayangan 0\% unsur rupa titik, garis, warna, tekstur, gelap terang, ruang, bidang, dan volume/gempal/bentuk 10,52\%. Unsur alam benda mendominasi unsur makna seni rupa berupa objek gambar ilustrasi.
\end{abstract}

Kata Kunci: bahasa, seni rupa, unsur-unsur seni, makna gambar, pendidikan karakter. 


\section{PENDAHULUAN}

Bahasa merupakan sarana komunikasi, baik itu secara lisan, tulisan maupun gambar. Kridalaksana (1993) mengemukakan bahasa adalah sistem lambang bunyi yang arbitrer yang digunakan oleh masyarakat untuk bekerja sama, berinteraksi, dan mengidentifikasikan diri. Bahasa digunakan manusia dalam segala aktivitasnya. Sejalan dengan definisi tersebut, pakar linguistik merumuskan banyak hakikat tentang bahasa. Rumusan tersebut akan menghasilkan sejumlah sifat atau ciri yang merupakan hakikat bahasa. Chaer (2014) mengemukakan sifatsifat bahasa antara lain: (1) sebuah sistem, (2) berwujud lambang, (3) berupa bunyi, (4) bersifat arbitrer, (5) bermakna, (6) bersifat konvensional, (7) bersifat unik, (8) bersifat universal, (9) bersifat produktif, (10) bervariasi, (11) bersifat dinamis, (12) berfungsi sebagai alat interaksi sosial, (13) merupakan identitas penuturnya.

Gambar merupakan bahasa yang universal dan telah berkembang sebelum ditemukannya bahasan tulisan. Sejak zaman prasejarah manusia telah mengenal gambar, hal tersebut terbukti dengan ditemukannya gambar dan lukisan di guagua tempat manusia saat itu tinggal. Seiring dengan perkembangan zaman dan peradaban manusia, seni menggambar juga mengalami perkembangan. Berdasarkan pengertian seni tersebut (Sulastianto, 2006), memberi kesimpulan bahwa seni merupakan sarana komunikasi perasaan dan pengalaman batin seseorang kepada kelompok masyarakatnya dalam rangka memenuhi kebutuhan pribadinya. Dapat disimpulkan bahwa dalam seni terdapat aspek-aspek yaitu manusia sebagai creator (pembuat) dan appreciator pemikat), karya yang dikreasikan beserta gagasan yang ada di dalamnya, dan komunikasi.

Gambar dijumpai dalam kehidupan kita sehari-hari, baik itu gambar bergerak maupun diam. Gambar tersebut dapat juga kita jumpai melalui media elektronik, maupun cetak seperti: majalah, novel, buku cerita, buku ilmu pengetahuan, bahkan karya ilmiah. Dikutip dari maxmanroe.com pengertian seni rupa adalah suatu cabang seni yang menghasilkan karya seni dimana bentuk dan kualitasnya dapat diraba oleh indera manusia, khususnya indera penglihatan dan indera peraba. Jika melihat wujud, seni rupa sangatlah bergantung pada unsur yang tampak atau dilihat pada karya. Unsur pembentuk rupa terdapat pada karya seni seperti gambar, lukisan, atau patung. Unsur garis dan warna adalah unsur terkecil yang membentuk seni rupa disebut sebagai unsur-unsur seni rupa. Unsurunsur lain dalam membentuk karya seni rupa diantaranya adalah : titik, bidang, volume, ruang, gelap terang, dan tekstur.

Nursantara (2007) mengemukakan gambar ilustrasi digunakan untuk membantu menjelaskan dan menghias karya sastra atau tulisan ilmiah, baik untuk kulit sampul atau halaman dalam. Karya ilustrasi biasanya menggambarkan isi dari hasil suatu karya tulisan seperti novel, cerpen, komik, karya ilmiah dan lain sebagainya. Sementara itu Adisasmito (2016) mengemukakan gambar ilustrasi merupakan media penyampaian pesan yang mempunyai misi tertentu.

Gambar tercipta atas dorongan imajinasi seniman/ilustratornya, terhadap suatu peristiwa, kisah, suasana, bahkan suatu kejadian yang sedang berlangsung maupun telah lampau. Kadang kala keberadaan gambar disertai dengan tulisan 
yang berupa kata maupun kalimat, akan tetapi ada kalanya berupa gambar saja tanpa sesuatu yang menyertainya.

Gambar ilustrasi kadang kala perwujudannya bukan sekedar hiburan saja, akan tetapi kadang kala berisi muatan politik, pendidikan, budaya, kesehatan, ekonomi, dan masalah sosial. Berdasarkan fungsinya seni rupa dikelompokkan menjadi dua jenis (Nursantara, 2007) yaitu: Seni Rupa Murni adalah jenis karya seni yang dibuat hanya sekedar untuk dinikmati keindahan atau estetikanya; Seni Rupa Terapan adalah jenis karya seni yang sangat meninggikan fungsi guna atau kegunaan dibandingkan keindahannya.

Kadang kala gambar ilustrasi yang ditampilkan menurut masyarakat pengemar dari suatu cerita perwujudannya terlalu berlebihan atau bahkan kurang mengena dan tidak mewakili maksud yang terkandung dalam narasi cerita. Hal tersebut kemungkinan karena illustrator kurang memahimi isi atau makna yang terkandung dalam Bahasa narasi cerita. Sehingga bahasa lisan maupun tulisan yang disampaikan menjadi sedikit samar. Mengakibatkan komunikasi kurang tersampaikan dengan baik. Sejauh penulis ketahui hal tersebut dilakukan oleh beberapa siswa-siswi yang masih duduk dibangku Sekolah Menengah Pertama maupun Atas. Ketika mereka diberi bacaan berupa narasi cerita, dan ditugaskan untuk membuat gambar ilustrasi berdasarkan narasi cerita yang ada sebagian siswa akan mengalami kesulitan, sehingga hasilnya kurang sesuai dengan harapan. Akan tetapi siswa-siswi tersebut memiliki antusias yang tinggi ketika melihat contoh gambar ilustrasi dari beberapa illustrator yang mereka lihat bahkan mereka ikuti kegiatan para illustrator tersebut di jejaring sosial seperti: facebook, instagram, maupun pinterest, bahkan bisa jadi di jalur Youtube. Akan tetapi mereka hanya sekedar suka dan hanya sekedar ingin mempelajari menggambar saja tanpa memperhatikan kandungan makna dalam narasi cerita.

\section{METODE}

Penelitian ini menggunakan metode penelitian konten analisis dalam menjaring dan memaparkan data yang telah didapat. Melalui penelitian kualitatif akan dicari hubungan makna yang terkandung dalam bahasa narasi cerita dengan bahasa visual dalam gambar ilustrasi, yang kemudian dideskripsikan dengan penelitian kualitatif untuk mendapatkan hasil analisis yang berfokus pada visualisasi gambar ilustrasi, penataan artistik, makna simbolik/pesan, dan tema yang ada pada gambar ilustrasi cerita.

Metode penelitian yang digunakan merupakan metode deskriptif kualitatif. Menurut Ratna (2008), metode deskriptif kualitatif adalah metode yang dilakukan dengan cara mendeskriptifkan fakta-fakta yang kemudian disusul dengan analisis. Metode kualitatif merupakan sebuah metode yang menghasilkan data deskriptif berupa kata-kata tertulis atau lisan dari narasi cerita dan bahasa visual dalam gambar ilustrasi cerita tersebut. Penelitian ini diarahkan untuk fokus memahami secara menyeluruh dan mendalam dari simbol dan ide gagasan pembentukan sketsa/rancangan gambar pada visualisasi gambar ilustrasi cerita, serta 
Vol. 4, No. 1, April 2021, pp. 78-86

p-ISSN: 2615-4935

e-ISSN: 2615-4943

memperoleh aspek edukatif yaitu nilai pendidikan karakter dalam tiap visualisasi karakter tokoh yang ditampilkan.

\section{HASIL DAN PEMBAHASAN}

\section{Hasil}

Tabel 1. Pengklasifikasian Unsur Seni Rupa, Makna, dan Aspek Edukatif

\begin{tabular}{|c|c|c|c|c|c|}
\hline $\begin{array}{l}\mathrm{N} \\
\mathrm{O}\end{array}$ & $\begin{array}{l}\text { Jenis } \\
\text { Cerita }\end{array}$ & $\begin{array}{l}\text { Judul } \\
\text { Cerita }\end{array}$ & $\begin{array}{l}\text { Unsur Seni } \\
\text { Rupa (objek } \\
\text { gambar) }\end{array}$ & $\begin{array}{c}\text { Makna } \\
\text { simbolik } \\
\text { (penokohan) }\end{array}$ & Aspek edukatif \\
\hline 1 & $\begin{array}{l}\text { Cerita } \\
\text { Bergamb } \\
\text { ar }\end{array}$ & $\begin{array}{l}\text { Penyu } \\
\text { Raksas } \\
\text { a dan } \\
\text { Pedaga } \\
\text { ng }\end{array}$ & $\begin{array}{l}\text { 1. Manusia } \\
\text { 2. Hewan } \\
\text { Laut } \\
\text { 3. Tumbuh } \\
\text { an } \\
\text { 4. Alam } \\
\text { benda }\end{array}$ & $\begin{array}{l}\text { 1. Netral } \\
\text { 2. protagon } \\
\text { is }\end{array}$ & $\begin{array}{l}\text { 1. Toleransi Religius } \\
\text { 2. Cinta damai Peduli } \\
\text { sosial Menghargai } \\
\text { prestasi } \\
\text { 3. Tanggung jawab } \\
\text { 4. Demokratis }\end{array}$ \\
\hline 2 & $\begin{array}{l}\text { Cerita } \\
\text { Pendek }\end{array}$ & Wasiat & $\begin{array}{l}\text { 1. Manusia } \\
\text { 2. Alam } \\
\text { benda } \\
\text { 3. Warna } \\
\text { 4. Garis }\end{array}$ & $\begin{array}{l}\text { 1. Netral } \\
\text { 2. protagon } \\
\text { is }\end{array}$ & $\begin{array}{l}\text { 1. Menghargai } \\
\text { prestasi } \\
\text { 2. Jujur } \\
\text { 3. Demokratis } \\
\text { 4. Disiplin } \\
\text { 5. Religious } \\
\text { 6. Kerja keras } \\
\text { 7. Bersahabat/komuni } \\
\text { katid } \\
\text { 8. Semangat } \\
\text { kebangsaan } \\
\text { 9. Gemar membaca } \\
\text { 10. Tanggung jawab }\end{array}$ \\
\hline 3 & $\begin{array}{l}\text { Cerita } \\
\text { Pendek }\end{array}$ & $\begin{array}{l}\text { Anak- } \\
\text { anak } \\
\text { Rimba }\end{array}$ & $\begin{array}{l}\text { 1. Tumbuh } \\
\text { an } \\
\text { 2. Alam } \\
\text { benda }\end{array}$ & $\begin{array}{l}\text { 1. Protagon } \\
\text { is } \\
\text { 2. Antagoni } \\
\mathrm{s}\end{array}$ & $\begin{array}{l}\text { 1. Peduli lingkungan } \\
\text { 2. Peduli sosial } \\
\text { 3. Rasa ingin tahu } \\
\text { 4. Cinta tanah air } \\
\text { 5. Jujur } \\
\text { 6. Mandiri } \\
\text { 7. Kerja keras } \\
\text { 8. Gemar membaca } \\
\text { 9. Disiplin } \\
\text { 10. Bersahabat/komuni } \\
\text { katif } \\
\text { 11. Tanggung jawab }\end{array}$ \\
\hline
\end{tabular}


Hasil penelitian berupa temuan dalam bentuk angka yaitu jumlah temuan dan persentase, serta pemaparan atau pembahasan mengenai unsur-unsur seni rupa dan kesamaan makna dalam simbolis gambar ilustrasi dengan narasi cerita sebagai sarana komunikasi sehingga mampu ditemukan pula adanya aspek edukatif berupa pendidikan karakter di dalamnya.

\section{Pembahasan}

Bahasa sebagai sistem lambang yang berwujud bunyi sudah pasti melambangkan suatu pengertian, suatu konsep, suatu ide atau suatu pikiran yang ingin disampaikan dalam wujud bentuk tertentu karena lambang-lambang itu mengacu pada suatu konsep, ide atau pikiran, maka dapat dikatakan bahwa bahasa itu memiliki simbol atau makna yang mampu memberikan gambaran fisik kepada pembaca lewat rangkaian kata dan kalimat serta adanya perwujudan gambar sebagai penguat dari kata atau kalimat tersebut.

Berikut ini penulis akan menjabarkan penafsiran dan uraian secara parafrase setiap data narasi cerita guna menemukan simbol dan unsur bentuk dalam gambar ilustrasi.

Temuan data unsur seni rupa berupa objek gambar ilustrasi, unsur makna dalam gambar ilustrasi dan aspek edukatif yang peneliti analisis di dalam narasi suatu cerita. Data berupa jumlah temuan dan persentase keseluruhan temuan, sebagai berikut.

Keterangan dari table 1 adalah sebagai berikut:

1. Unsur Seni Rupa berupa bentuk Objek Gambar Ilustrasi, antara lain: manusia, hewan, tumbuhan, alam benda, bayang-bayang dan bayangan

2. Unsur Rupa : titik, garis, warna, tekstur, gelap terang, ruang, bidang, dan volume/gempal/bentuk

Berdasarkan data tersebut dapat penulis rekap temuan dan persentase sebagai berikut:

a. Rekapitulasi berupa temuan unsur-unsur seni rupa yang membentuk suatu objek gambar dalam karya ilustrasi dari ketiga cerita diatas dapat penulis persentase dalam tabel berikut :

Tabel 2. Rekapitulasi Unsur Seni Rupa dalam Bentuk Objek Gambar Ilustrasi

\begin{tabular}{|c|c|c|c|}
\hline No. & Unsur Rupa & Jumlah Temuan & Persentase \\
\hline 1 & Manusia & 9 & $23.7 \%$ \\
\hline 2 & Hewan & 7 & $18.42 \%$ \\
\hline 3 & Tumbuhan & 4 & $10.52 \%$ \\
\hline 4 & Alam Benda & 14 & $36.84 \%$ \\
\hline 5 & $\begin{array}{l}\text { Bayang-bayang dan } \\
\text { Bayangan }\end{array}$ & 0 & $0 \%$ \\
\hline 6 & $\begin{array}{l}\text { Titik, garis, warna, dsbg. } \\
\text { Jumlah }\end{array}$ & $\begin{array}{r}4 \\
38\end{array}$ & $\begin{array}{c}10.52 \% \\
100 \%\end{array}$ \\
\hline
\end{tabular}


b. Rekapitulasi berupa temuan unsur simbolik/makna yang membentuk suatu objek gambar dalam karya ilustrasi dari ketiga cerita diatas dapat penulis persentase dalam tabel berikut:

Tabel 3. Rekapitulasi Unsur Simbolik/Makna Dalam Objek Gambar Ilustrasi

\begin{tabular}{clcc}
\hline No. & Unsur Simbolik/makna & Jumlah Temuan & Persentase \\
\hline 1 & Netral & 2 & $33.3 \%$ \\
2 & Baik (Protagonis) & 3 & $50 \%$ \\
3 & Jahat (Antagonis) & 1 & $16.7 \%$ \\
& Jumlah & 6 & $100 \%$ \\
\hline
\end{tabular}

c. Rekapitulasi berupa temuan dalam aspek edukatif/pesan moral dalam narasi dari ketiga cerita diatas dapat penulis persentase dalam tabel berikut:

Tabel 4. Rekapitulasi Aspek Edukatif/Pesan Moral

$\begin{array}{ccc}\text { Aspek Edukatif } & \text { Jumlah Temuan } & \text { Persentase }\end{array}$

\begin{tabular}{|c|c|c|}
\hline 1. Religius & 3 & $8 \%$ \\
\hline 2. Jujur (moral) & 2 & $6 \%$ \\
\hline 3. Toleransi & 3 & $8 \%$ \\
\hline 4. Disiplin & 2 & $6 \%$ \\
\hline 5. Kerja Keras & 2 & $6 \%$ \\
\hline 6. Kreatif & 0 & $0 \%$ \\
\hline 7. Mandiri & 1 & $3 \%$ \\
\hline 8. Demokratis & 3 & $8 \%$ \\
\hline 9. Rasa Ingin Tahu & 1 & $3 \%$ \\
\hline 10. Semangat Kebangsaan & 1 & $3 \%$ \\
\hline 11. Cinta Tanah Air & 1 & $3 \%$ \\
\hline 12. Menghargai Prestasi & 4 & $11 \%$ \\
\hline 13. Bersahabat/Komunikatif & 2 & $6 \%$ \\
\hline 14. Cinta Damai & 2 & $6 \%$ \\
\hline 15. Gemar Membaca & 2 & $6 \%$ \\
\hline 16. Peduli Lingkungan & 1 & $3 \%$ \\
\hline 17. Peduli Sosial & 3 & $8 \%$ \\
\hline 18. Tanggung Jawab & 3 & $8 \%$ \\
\hline Jumlah & 36 & $100 \%$ \\
\hline
\end{tabular}

Hasil matriks tabel rekapitulasi dan persentase temuan unsur imaji, unsur simbol, dan aspek edukatif di atas dapat diperoleh dengan menggunakan rumus atau perhitungan: 


$$
\sum=\frac{y}{x} \times 100
$$

Keterangan:

$\sum=$ data yang dicari

$\mathbf{y}=$ jawaban dari data

$\mathbf{x}=$ jumlah sampel

Berikut ini merupakan penjabaran data di atas berdasarkan gambar dari ketiga judul cerita:

a. Penyu Raksasa dan Pedagang

Menceritakan tentang kebaikan, tanggung jawab, sifat peduli, dari seekor penyu raksana yang rela menolong sesama makhluk hidup meskipun nyawa taruhannya.

Mendengarkan keluh kesah dari para pedagang yang dibantunya dengan iklas dan tanpa pamrih. Penyu raksas percaya bahwa yang dilakukannya adalah kehendak dari Tuhan.

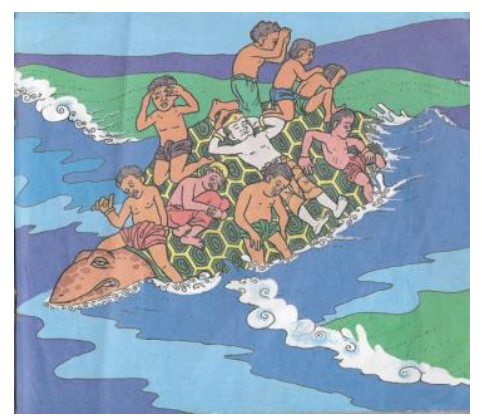

\section{Gambar 1. Penyu Raksasa dan Pedagang, cerita bergambar Sumber: Singo, 2000}

b. Wasiat

Menceritakan tentang perjuangan, kedisiplinan, tanggung jawab dan kejujuran seorang guru terhadap masa depan generasi muda untuk bekal dikemudian hari. Beliau meninggalkan pesan yang dianggap sebagai wasiat untuk generasinya agar menjadi seorang pendidik yang jujur, bertanggung jawab dan disiplin.

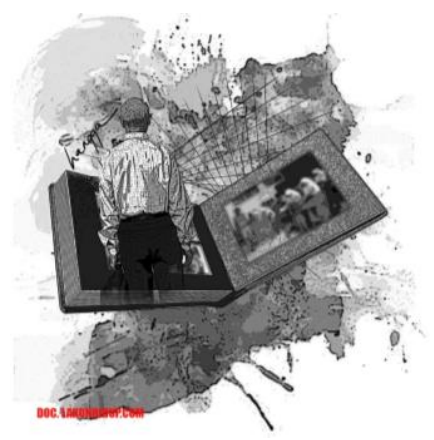

Gambar 2. Wasiat ilustrasi, cerita pendek Sumber: Espe, 2020 


\section{c. Anak-anak Rimba}

Menceritakan persahabatan dari tiga anak di Rimba Cempaya untuk mempertahankan tanah kelahiran, menjaga, melindungi dan melestarikannya dengan cara mereka. Akan tetapi pada akhirnya cara mereka menjalankan kehidupan untuk menjaga tanah kelahiran menjadi berlawanan walaupun tujuannya sama.

Cerita ini memiliki maksud agar generasi muda secara bersama-sama menjaga, melestarikan, melindungi dan membangun daerahnya dengan baik agar semua lapisan masyarakat yang tinggal didalamnya sejahtera dan memiliki pendidikan yang baik pula.

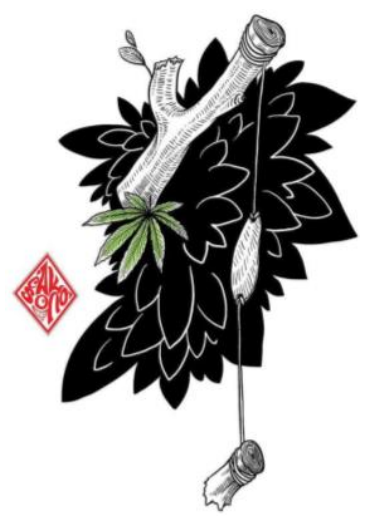

\section{Gambar 3. Anak-Anak Rimba, cerita pendek Sumber: Muhammad, 2020}

\section{SIMPULAN}

Berdasarkan hasil penelitian dan pembahasan antara bahasa yang berupa narasi cerita dengan unsur-unsur seni rupa sebagai pembentuk gambar ilustrasi cerita dapat disimpulkan bahwa terdapat makna bahasa dalam gambar ilustrasi cerita. Hal ini dibuktikan dengan terdapat unsur simbolik/makna dalam gambar ilustrasi berupa unsur simbol/makna netral 33,3\% Baik (protagonis) 50\% Jahat (Antagonis) 16,7\%. Unsur simbolik/makna yang menggambarkan tokoh berkarakter baik(protagonis) mendominasi dalam gambar ilustrasi, dan ditemukan pula aspek edukatif di dalam narasi cerita berupa pendidikan karakter religious $8 \%$ Jujur 6\% Toleransi $8 \%$ disiplin $6 \%$ kerja keras $6 \%$ kreatif $0 \%$ mandiri $3 \%$ demokratis $8 \%$ rasa ingin tahu 3\% semangat kebangsaan 3\% cinta tanah air 3\% menghargai prestasi $11 \%$ bersahabat/komunikatuf 6\% Peduli lingkungan 3\% peduli sosial $8 \%$ dan tanggung jawab $8 \%$. Aspek nilai pendidikan karakter yang berhubungan dengan menghargai prestasi mendominasi di dalam narasi cerita. Terdapat makna seni rupa dalam gambar ilustrasi cerita. Hal ini dibuktikan dengan terdapat unsur makna seni rupa berupa objek gambar ilustrasi yang meliputi unsur rupa manusia $23,7 \%$ unsur rupa hewan $18,42 \%$ unsur rupa tumbuhan 10,52\% unsur rupa Alam benda 36,84\% Unsur rupa bayang-bayang dan bayangan $0 \%$ unsur rupa titik, garis, warna, tekstur, gelap terang, ruang, bidang, 
dan volume/gempal/bentuk 10,52\%. Unsur alam benda mendominasi unsur makna seni rupa berupa objek gambar ilustrasi.

\section{DAFTAR PUSTAKA}

Adisasmito, N. Y. D. (2016). komunikasi visual gambar ilustrasi tradisi pada naskah tua Jawa masa kolonialisme. Jurnal Kajian Seni, 2(2), 95-106.

Chaer, A. (2014). Linguistik umum. Jakarta: Rineka Cipta.

Espe, M. S. (11 Oktober 2020). Wasiat [Cerpen Suara Merdeka]. Diakses dari http://lakonhidup.com/2020/10/11/wasiat/.

Kridalaksana, H. (1993). Kamus linguistik. Edisi Ketiga. Jakarta: PT Gramedia Pustaka.

Maxmanroe. (Tanpa Tahun). Seni Rupa: Pengertian, unsur-unsur, fungsi, dan jenisnya. Diakses dari http://www.maxmanroe,com/vid/umum/senirupa,html.

Muhammad, D. (11 Oktober 2020). Anak-anak Rimba [Cerpen Media Indonesia]. Diakses dari http://lakonhidup.com/2020/10/11/anak-anak-rimba/.

Nursantara, Y. (2007). Seni budaya untuk SMA kelas X. Bekasi: Erlangga.

Ratna, N. K. (2008). Teori, metode dan teknik penelitian sastra. Yogyakarta: Pustaka Pelajar.

Singo, D. (2000). Penyu raksasa dan pedagang. Jakarta: Grasindo.

Sulastianto, H. (2006). Seni budaya untuk kelas X SMA. Bandung: Grafindo Media Pratama. 